Note

\title{
A layer of ozone detected in the nightside upper atmosphere of Venus
}

\author{
F. Montmessin ${ }^{\mathrm{a}, *}$, J.-L. Bertaux $^{\mathrm{a}}$, F. Lefèvre ${ }^{\mathrm{a}}$, E. Marcq ${ }^{\mathrm{a}}$, D. Belyaev ${ }^{\mathrm{a}, \mathrm{b}}$, J.-C. Gérard $^{\mathrm{c}}$, O. Korablev ${ }^{\mathrm{b}}$, \\ A. Fedorova ${ }^{\text {b }}$, V. Sarago ${ }^{\text {a }}$, A.C. Vandaele ${ }^{\mathrm{d}}$
}

${ }^{a}$ LATMOS - UVSQ/CNRS/IPSL, 11 bd d'Alembert, 78280 Guyancourt, France

${ }^{\mathrm{b}}$ Space Research Institute (IKI) - Profsoyuznaya 84/32, Moscow 117997, Russia

${ }^{\mathrm{C}}$ LPAP - Université de Liège, 5 Avenue de Cointe, 4000 Liège, Belgium

${ }^{\mathrm{d}}$ IASB-BIRA - Avenue Circulaire 3, 1180 Brussels, Belgium

\section{A R T I C L E I N F O}

\section{Article history:}

Received 24 February 2011

Revised 12 August 2011

Accepted 13 August 2011

Available online 25 August 2011

\section{Keywords:}

Atmospheres, Chemistry

Atmospheres, Composition

Occultations

Venus, Atmosphere

Spectroscopy

\begin{abstract}
A B S T R A C T
To date, ozone has only been identified in the atmospheres of Earth and Mars. This study reports the first detection of ozone in the atmosphere of Venus by the SPICAV ultraviolet instrument onboard the Venus Express spacecraft. Venusian ozone is characterized by a vertically confined and horizontally variable layer residing in the thermosphere at a mean altitude of $100 \mathrm{~km}$, with local concentrations of the order of $10^{7}-10^{8}$ molecules $\mathrm{cm}^{-3}$. The observed ozone concentrations are consistent with values expected for a chlorine-catalyzed destruction scheme, indicating that the key chemical reactions operating in Earth's upper stratosphere may also operate on Venus.
\end{abstract}

(C) 2011 Elsevier Inc. All rights reserved.
Ozone is a molecule of fundamental photochemical and exobiological interest. Its absorption continuum in the spectral region between 200 and $300 \mathrm{~nm}$, also known as the Hartley band, is a remarkable spectroscopic ultraviolet (UV) feature as it is both spectrally broad and intense. For this reason, the presence of ozone in a given atmosphere provides efficient filtering of the energetic ultraviolet radiation that reaches the top of the atmosphere. On Earth, $90 \%$ of ozone is contained in a so-called stratospheric "ozone layer" located between 15 and $50 \mathrm{~km}$. In fact, ozone is responsible for the very existence of the temperature inversion which defines the Earth's stratosphere, temperature in this altitude range being controlled by solar energy absorbed in the Hartley band. Stratospheric ozone plays a critical role for Earth habitability, reducing ultraviolet to doses acceptable for life development and maintenance. Its formation is controlled by the following reactions:

$\mathrm{O}_{2}+\mathrm{h} v \rightarrow \mathrm{O}+\mathrm{O}$

$\mathrm{O}_{2}+\mathrm{O}+\mathrm{M} \rightarrow \mathrm{O}_{3}+\mathrm{M}$

where (2) is the sole reaction producing ozone, with M denoting a third body required to carry away excess vibrational energy. $\mathrm{O}_{3}$ production is therefore uniquely dictated by the availability of oxygen molecules, which considering the large reservoir of $\mathrm{O}_{2}$ on Earth (21\% of the atmospheric composition) allows ozone to be sustained at high abundances ( $3 \mathrm{~mm}$-atmosphere on average, Brasseur and Solomon, 2005). Note that the $\mathrm{mm}$-atmosphere unit measures the vertically integrated column abundance of a given species if brought down to the surface. Ozone abundance is also expressed by the Dobson Unit (DU, one Dobson unit is equivalent to a layer of ozone that would be $10 \mu \mathrm{m}$ thick under standard terrestrial temperature and pressure); i.e. $2.69 \times 10^{16}$ molecules $\mathrm{cm}^{-2}$.

The build-up of oxygen on Earth up to the present-day concentration is subsequent to the Great Oxidation Event (GOE) that took place 2.4 billion year ago. The exact causes of the GOE are still not entirely elucidated, but may have involved a

\footnotetext{
* Corresponding author.

E-mail address: franck.montmessin@latmos.ipsl.fr (F. Montmessin).
}

complex interplay between the biological, geophysical and chemical activities of the planet (Farquhar et al., 2000; Catling et al., 2001). Ozone has been identified on Mars since the early 1970s (Barth and Hord, 1971). There, $\mathrm{O}_{2}$ comes almost uniquely from the photolysis of $\mathrm{CO}_{2}$. However, catalytic cycles driven by $\mathrm{HO}_{X}$ radicals (the sum of all hydrogen oxides), efficiently convert $\mathrm{O}_{2}$ back to $\mathrm{CO}_{2}$, limiting $\mathrm{O}_{2}$ to a minor fraction $(0.1 \%)$ of the atmospheric inventory. Ozone abundance is consequently low on Mars ( $<10 \mu \mathrm{m}$-atmosphere or $<1 \mathrm{DU})$, typically 300 times less than on the Earth. In spite of its scarcity, martian ozone is a key tracer of the photochemistry that regulates the composition of Mars atmosphere. Through its reaction with $\mathrm{HO}_{X}$ radicals, it appears closely tied to the photochemistry of water and exhibits a strong temporal and spatial anti-correlation with gaseous $\mathrm{H}_{2} \mathrm{O}$, as evidenced by SPICAM onboard Mars Express (Perrier et al., 2006), consistently with model predictions (Lefèvre et al., 2004).

On Venus, the presence of the thick sulfuric acid clouds makes it particularly difficult to probe the atmosphere below $60 \mathrm{~km}$, except in a few infrared windows (Allen and Crawford, 1984). Above the clouds however, ozone was until now not detected despite a total atmospheric density similar to that of the Earth's stratosphere, which suggests it is significantly less abundant than on Earth. The detection that is reported here was made with the Spectroscopy for Investigation of Characteristics of the Atmosphere of Venus (SPICAV) instrument. SPICAV is a remote-sensing spectrometer covering three distinct spectral regions from ultraviolet to mid-infrared that is used to probe the atmosphere above the clouds. It has orbited around Venus onboard the Venus Express spacecraft (Bertaux et al., 2007) since April 2006 (Svedhem et al., 2007). The ultraviolet part of the SPICAV suite probes the 110 $320 \mathrm{~nm}$ range with a spectral resolution of $1.5 \mathrm{~nm}$. Here, resolution is defined as the full width at half maximum of the spectrometer point spread function. The instrument is sensitive to a large variety of source brightness, ranging from faint stars to the bright Sun. The present work is based on the results of stellar occultations which have been discussed in the case of Mars with SPICAM (Bertaux et al., 2006; Montmessin et al., 2006; Lebonnois et al., 2006), and which have already been presented for Venus (Bertaux et al., 2007). Stellar occultation allows one to infer vertical profiles of aerosols and $\mathrm{CO}_{2}$ density (the main atmospheric constituent) between 80 and $140 \mathrm{~km}$, a region covering the upper mesosphere and the lower 
thermosphere (Bertaux et al., 2007). Our observations were performed on the nightside of Venus. Several attempts were made on the sunlit hemisphere, but the stellar signal could not be correctly isolated from the bright foreground of the limb due to solar scattering by aerosols.

A detailed inspection of the complete SPICAV dataset allowed to visually identify ozone UV absorption from a stellar occultation sequence during orbit \#348 at an altitude of $103 \mathrm{~km}$ (Fig. 1). The ozone signature emerges as a moderate, yet distinct reduction of the atmospheric transmission between 220 and $280 \mathrm{~nm}$, with a maximum around $250 \mathrm{~nm}$, consistent with the Hartley band structure. In this spec trum, ozone absorbs $4 \%$ of the stellar signal at the band center (Fig. 1D), produced by a slant number density of $8.2 \times 10^{15}$ molecules of ozone $\mathrm{cm}^{-2}(\sim 0.3 \mathrm{DU})$ along the line of sight. A factor of $\sim 1 / 50$ must be applied to convert tangentially integrated densities to vertically integrated densities.

A positive ozone identification is established when the sum of squared residuals in the $220-280 \mathrm{~nm}$ range is decreased by a factor of two when the ozone Hartley band is included in the retrieval, yielding a $>5-\sigma$ confidence level. Instrument signal-to-noise ratio $(S N R)$ is evaluated independently for each occultation sequence by consideration of the intrinsic variability of the $\sim 1000$ spectra of the star recorded before the occultation by the atmosphere and by the planet. For each spectral element (i.e. pixel), a robust estimator of the mean $M_{s}$ and of the variance $V_{s}$ of the signal is obtained that allows to subsequently infer the instrumental gain $G$ (defined as $M_{s}=G V_{s}$ ) with a linear fit of the $M_{s}$ vs. $V_{s}$ scatter plot. SPICAV SNR for each pixel is given by $M_{s} / \sqrt{ }\left(G V_{s}\right)$; yielding an in-flight verified value of $S N R /$ pixel $>50$ for a bright UV star (e.g. $\xi \mathrm{CEN})$, confirming the theoretical estimations made by Korablev et al. (2001) for SPICAV-concept instruments. Sources of noise subsequent to CCD read-out and CCD dark-current have a minor contribution $(<10 \%)$ to the noise of SPICAV spectra (at least those containing ozone signature), which are essentially dominated by shot-noise. Data errors are then propagated throughout the extraction process of the abundance of the chemical constituents of interest (e.g. ozone). Uncertainties on the end products of the retrieval (ozone column abundances) are eventually given by the square root of the diagonal terms in the free parameter space covariance matrix computed by the Levenberg-Marquardt chi-square minimization algorithm. 29 different orbits bear the unambiguous signature of ozone, out of a total of more than 286 .

For orbit \#348, an ozone signature at $103 \mathrm{~km}$ is not firmly identified in the adjacent spectra recorded $5 \mathrm{~km}$ below and $5 \mathrm{~km}$ above the detection altitude. This implies that ozone exists as a discrete layer confined within $5-10 \mathrm{~km}$ of altitude. This vertical layering is generally verified for the other 28 orbits where ozone has been detected (Fig. 2-left). The ozone layer is even more prominent in the local concentration profiles that are obtained after vertical inversion of the integrated abundance. The conversion from slant-integrated abundances to local concentrations of ozone is performed via standard onion-peeling procedure. On a few orbits, several consecutive spectra exhibit a firm ozone signature: four detections spanning the 92-105 $\mathrm{km}$ range are made on orbit \#204, resulting in a $\mathrm{O}_{3}$ local concentration peak of $6 \times 10^{7}$ molecules $\mathrm{cm}^{-3}$ at $92 \mathrm{~km}$ (Fig. 2-right). Here, the layer is characterized by a factor of two decrease of ozone concentration $5 \mathrm{~km}$ below and $5 \mathrm{~km}$ above the peak. On average, the retrieved local concentrations range between $10^{7}$ and $10^{8}$ molecules $\mathrm{cm}^{-3}$ at a pressure of $1 \mu \mathrm{bar}$, yielding $0.1-1 \mathrm{ppmv}$ in mixing ratios.

The theoretical presence of ozone on Venus has been investigated by means of one dimensional photochemistry models (Yung and DeMore, 1982, 1999; Krasnoposly,
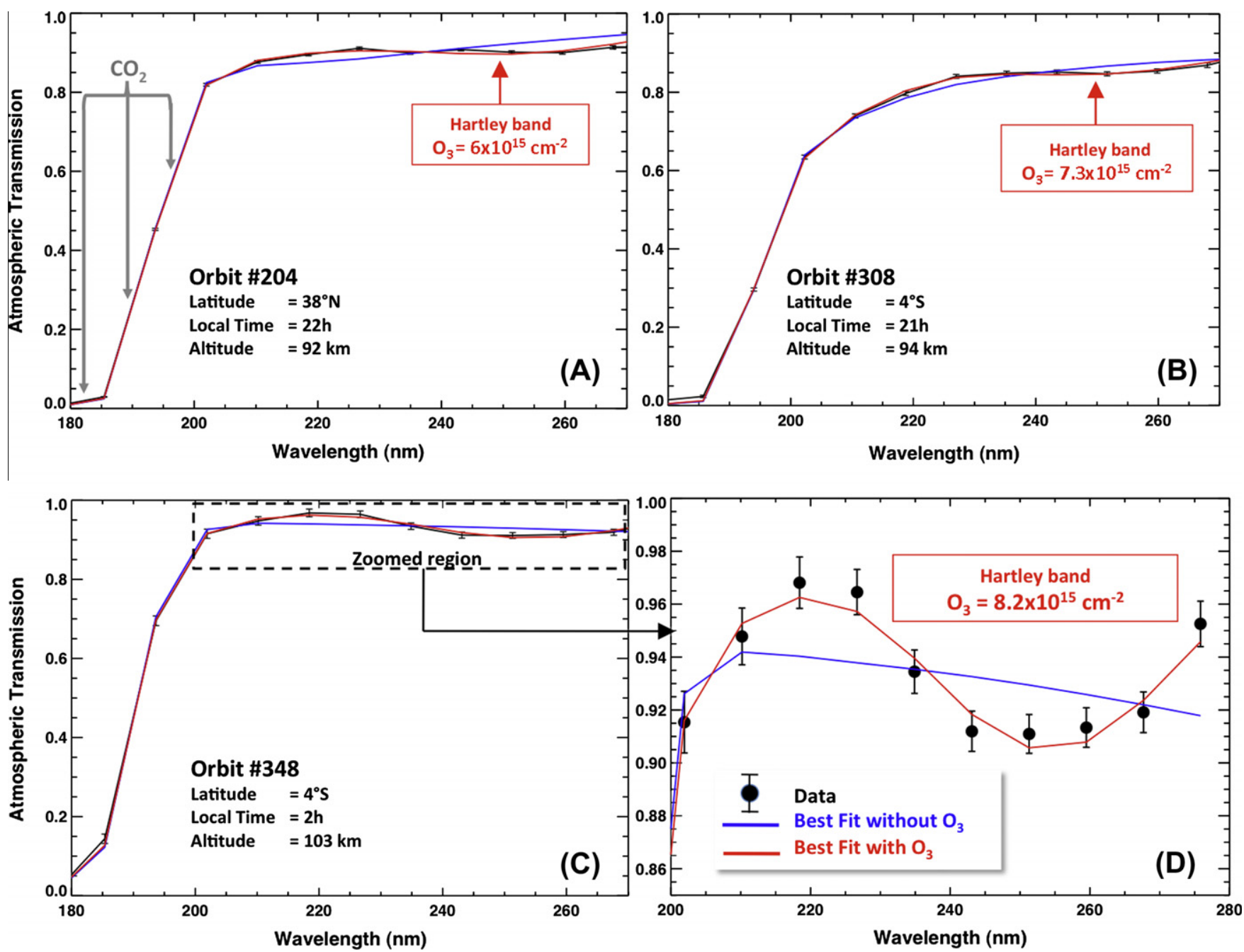

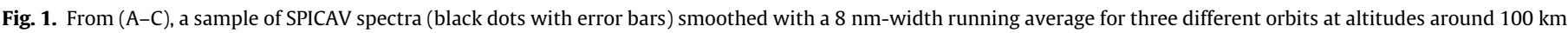



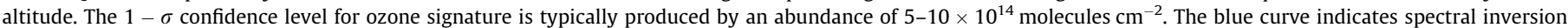

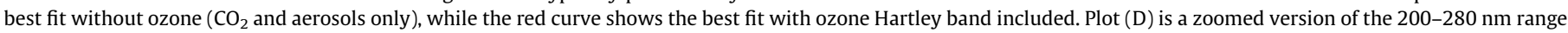

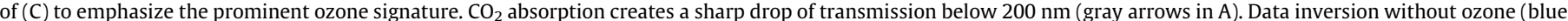
curves) is unable to reproduce the transmission feature between 220 and $280 \mathrm{~nm}$, resulting in a spectrally flat continuum across the $\mathrm{O}_{3}$ absorption range. 

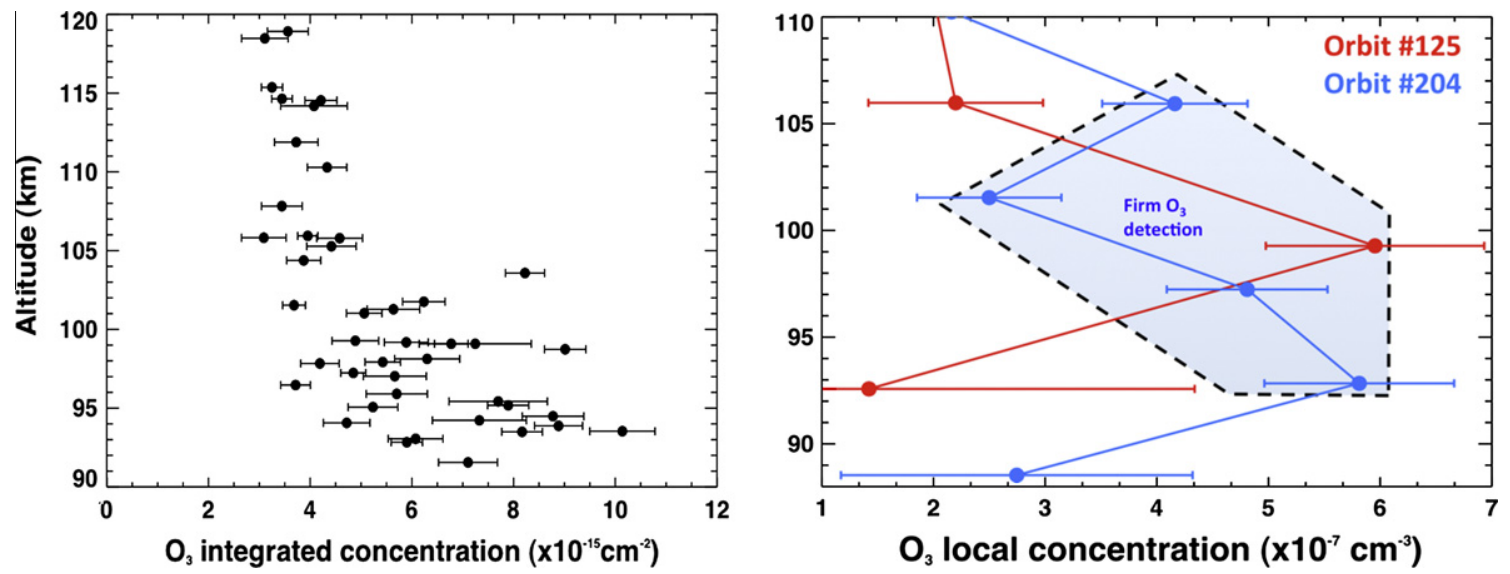








the light blue shaded area. Both profiles show that ozone peaks between 90 and $100 \mathrm{~km}$, decreasing above and below, indicating a distinct layered shape.

2010). During the night, $\mathrm{O}_{3}$ formation via the $\mathrm{O}_{2}+\mathrm{O}$ reaction is balanced by its loss through the following main reactions:

$$
\begin{aligned}
& \mathrm{O}_{3}+\mathrm{O} \rightarrow \mathrm{O}_{2}+\mathrm{O}_{2} \\
& \mathrm{O}_{3}+\mathrm{H} \rightarrow \mathrm{O}_{2}+\mathrm{OH}^{*} \\
& \mathrm{O}_{3}+\mathrm{OH} \rightarrow \mathrm{HO}_{2}+\mathrm{O}_{2} \\
& \mathrm{O}_{3}+\mathrm{Cl} \rightarrow \mathrm{O}_{2}+\mathrm{ClO} \\
& \mathrm{O}_{3}+\mathrm{NO} \rightarrow \mathrm{NO}_{2}+\mathrm{O}_{2} \\
& \mathrm{O}_{3}+\mathrm{S} \rightarrow \mathrm{SO}+\mathrm{O}_{2}
\end{aligned}
$$

Reaction (4), which constitutes part of the Bates-Nicolet mechanism, has been advocated to explain the $\mathrm{OH}$ emission feature in the near-infrared (at 1.46 and $2.81 \mu \mathrm{m}$ ) observed by VIRTIS on Venus Express (Piccioni et al., 2008; Migliorini et al., 2010; Soret et al., 2010). The $\mathrm{OH}(1-0)$ Meinel band emits at an average altitude of $96 \mathrm{~km}$. This is consistent with our measurements which indicate a detection altitude for ozone varying between 90 and $120 \mathrm{~km}$ with a mean value of $99 \mathrm{~km}$ (Fig. 2-left). The product of concentrations of ozone with hydrogen required to match $\mathrm{OH}$ emission is of $4-9 \times 10^{15} \mathrm{~cm}^{-6}$. With a hydrogen density predicted of around
$10^{8} \mathrm{~cm}^{-3}$ (Yung and DeMore, 1999), the required ozone density should be 4$9 \times 10^{7} \mathrm{~cm}^{-3}$ (note however that this crude estimation makes no case of the potential influence of quenching-led deexcitation process), lying in the same range as the concentrations reported here.

The spatial distribution of our ozone detections does not exhibit any specific pattern (Fig. 3). The $\mathrm{OH} \mathrm{(1-0)} \mathrm{emission} \mathrm{distribution} \mathrm{reported} \mathrm{by} \mathrm{VIRTIS} \mathrm{is} \mathrm{similarly}$ featureless, suggesting an overwhelming influence of chemistry over transport (Piccioni et al., 2008; Migliorini et al., 2010). Essentially found in the evening side of the southern hemisphere, ozone detections are scattered between the equator and $\sim 40^{\circ}$ S. The uneven coverage of SPICAV occultation is not suited to reliably address temporal and spatial variability, yet the absence of firm $\mathrm{O}_{3}$ detections at the anti-solar point is a puzzling feature of our dataset. The formation of ozone depends primarily on the availability of oxygen atoms and molecules and as such may be expected to correlate with $\mathrm{O}_{2}\left({ }^{1} \Delta\right)$ nightglow emission which concentrate in the anti-solar region near $96 \mathrm{~km}$ (Drossart et al., 2007; Piccioni et al., 2009). $\mathrm{O}_{2}$ nightglow results from the recombination of oxygen atoms that originate from the dayside through $\mathrm{CO}_{2}$ photolysis and that are further advected by the sub-solar-to-antisolar (SSAS) thermospheric circulation. A possible explanation for the

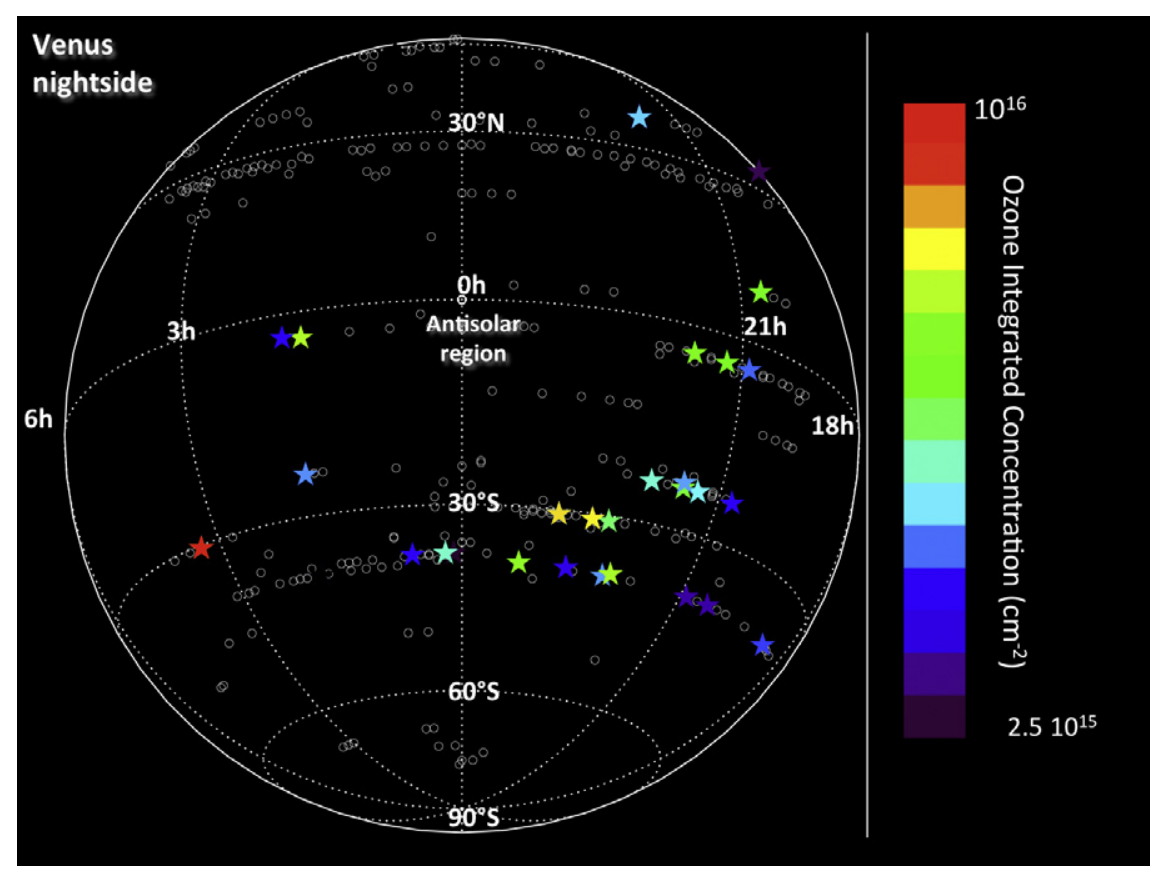






maximum in column abundance in the antisolar region where the thermospheric circulation subsides and the $\mathrm{O}_{2}$ airglow emission concentrates. 
lack of $\mathrm{O}_{3}$ detection in the antisolar region is the presence in the SSAS of large amounts of chlorine radicals produced on the dayside by the photolysis of $\mathrm{HC}$ (Yung and DeMore, 1999). Reaction (6) of $\mathrm{O}_{3}$ with chlorine is in principle the dominant loss term for ozone (Yung and DeMore, 1999; Krasnoposly, 2010). Consequently, the potentially chlorine-rich airmasses of the subsiding circulation in the antisolar region might prevent the buildup of measurable amounts of $\mathrm{O}_{3}$. Ozone destruction might also be intensified in the adiabatically warmed environment of the descending branch of the SSAS (Bertaux et al., 2007; Bailey et al., 2008) due to the temperature dependence of reaction (6). The model of Yung and DeMore (1999) predicts that ozone vertical distribution is maximal at $96 \mathrm{~km}$ with a second peak near $65 \mathrm{~km}$. Below $75 \mathrm{~km}$ however, the stellar signal is lost due to the presence of the opaque sulfuric acid aerosols. A secondary peak at $65 \mathrm{~km}$, if it exists can thus not be sampled by SPICAV. The altitude of the main peak along with their estimate for concentration of $1-2 \times 10^{7} \mathrm{~cm}^{-3}$ is in line with our measurements. These values do however conflict with the nightside photochemical model of Krasnoposly (2010) which predicts 200 times more ozone and exhibits a very sharp peak. The latter appears controlled by the shapes of the corresponding predicted $\mathrm{O}$ and $\mathrm{O}_{2}$ profiles (displayed in his Fig. 8), showing an abrupt decrease of $\mathrm{O}$ atoms below $90 \mathrm{~km}$ and a more gradual decrease of $\mathrm{O}_{2}$ above that level. The ozone overestimation in Krasnoposly's model likely results from specifying a chlorine concentration weaker than Yung and DeMore (1999).

Our observations thus bring new evidence that the equilibrium of oxygen species in the upper atmosphere of Venus is dominated by the same chlorine-catalyzed destruction cycles that prevails in Earth's stratosphere. This underlines the importance of day to night circulation in the upper atmosphere and its coupling with chemistry when thermospheric air containing $\mathrm{O}, \mathrm{Cl}$ and $\mathrm{N}$ atoms descends on the night side. Together with $\mathrm{O}_{2} 1.27 \mu \mathrm{m}$ and $\mathrm{NO} \gamma$ and $\delta$ bands (Gérard et al., 2008), our observations of ozone will constrain 3D models of this region of Venus. The direct relation between ozone and molecular oxygen makes ozone a unique proxy for estimating $\mathrm{O}_{2}$ abundance in planetary atmospheres, which is otherwise challenging to detect directly (except for an absorption feature at $761 \mathrm{~nm}$; Kaltenegger et al. 2007). In the field of exoplanets, the $\mathrm{O}_{3}-\mathrm{CO}_{2}-\mathrm{O}_{2}$ triplet detection is considered to be a robust biomarker signature that can be used to distinguish between abiotic and biotic production of oxygen (Selsis et al., 2002; Segura et al., 2007). For Mars, Selsis et al. (2002) estimated that an ozone concentration greater than $20 \%$ of the Earth's value would be needed to establish the existence of biological oxidizing agents. Our observations contribute to the growing characterization of the atmospheric composition of the Solar System bodies, and show that on Venus as on Mars, the positive identification of this triplet is not associated with a biological activity on this planet. The Venusian ozone layer that is reported here appears too tenuous ( $>0.02 \mathrm{DU}$, value obtained after vertical integration of the local concentrations measured by SPICAV) to efficiently filter out UV radiation and protect organisms if they were to develop below. On Earth, emerging life eventually modified its environment, disrupting chemical equilibrium in a sustainable manner: oxygen photosynthesized by cyanobacteria eventually led to the formation of an optically thick and thus protective layer of ozone. Such a positive feedback has not occurred on Venus or Mars, or if it has, eventually vanished.

\section{Acknowledgments}

Venus Express is a space mission from ESA (European Space Agency). We wish to thank CNES, CNRS and Université Versailles St Quentin en Yvelines for funding SPICAV in France and supporting the present analysis. J.C.G. is supported by the Belgian Fund for Scientific Research (FNRS). IASB-BIRA would like to acknowledge support by the Belgian Federal Science Policy Office and the European Space Agency (ESA, PRODEX program, Contracts C 90268, 90113, and 17645).

\section{References}

Allen, D., Crawford, J., 1984. Cloud structure on the dark side of Venus. Nature 307, 222-224.

Bailey, J., Meadows, V.S., Chamberlain, S., Crisp, D., 2008. The temperature of the Venus mesosphere from $\mathrm{O}_{2}\left(\mathrm{a}^{1} \Delta_{\mathrm{g}}\right)$ airglow observations. Icarus 197, 247-259.

Barth, C.A., Hord, C.W., 1971. Mariner ultraviolet spectrometer. Science 173, 795796.

Bertaux, J.-L. et al., 2006. Introduction to the special section: Observations of the atmosphere of Mars with SPICAM spectrometers on board Mars Express. J. Geophys. Res. 111. doi:10.1029/2006JE002760.

Bertaux, J.-L. et al., 2007. A warm layer in Venus'cryosphere and high-altitude measurements of $\mathrm{HF}, \mathrm{HCl}, \mathrm{H}_{2} \mathrm{O}$ and HDO. Nature 450, 646-649. doi:10.1038/ nature05974.

Brasseur, G., Solomon, S., 2005. Aeronomy of the Middle Atmosphere: Chemistry and Physics of the Stratosphere and Mesosphere. Kluwer Academic Publisher.

Catling, D., Zahnle, K., McKay, C., 2001. Biogenic methane, hydrogen escape, and the irreversible oxidation of early Earth. Science 293, 839-843. doi:10.1126/ science. 1061976.

Drossart et al., 2007. A dynamic upper atmosphere of Venus as revealed by VIRTIS on Venus Express. Nature 450, 641-645.

Farquhar, J., Bao, H., Thiemens, M., 2000. Atmospheric influence of Earth's earliest sulfur cycle. Science 289, 756-758.

Gérard et al., 2008. Limb observations of the ultraviolet nitric oxide nightglow with SPICAV on board Venus Express. J. Geophys. Res. 113. doi:10.1029/ 2008JE003078.

Kaltenegger, L., Traub, W.A., Jucks, K.W., 2007. Spectral evolution of an Earth-like planet. Astrophys. J. 658, 598-616.

Korablev, O.I., Bertaux, J.-L., Dubois, J.-P., 2001. Occultation of stars in the UV: Study of the atmosphere of Mars. J. Geophys. Res. 106, 7597-7610.

Krasnoposly, V.A., 2010. Venus night airglow: Ground-based detection of $\mathrm{OH}$, observations of $\mathrm{O}_{2}$ emissions, and photochemical model. Icarus 207, 17.

Lebonnois et al., 2006. Vertical distribution of ozone on Mars as measured by SPICAM/Mars Express using stellar occultations. J. Geophys. Res. 111. doi:10.1029/2005JE002643.

Lefèvre, F., Lebonnois, S., Forget, F., Montmessin, F., 2004. Three dimensional modeling of ozone on Mars. J. Geophys. Res. 119. doi:10.1029/2004JE002268.

Migliorini, A. et al., 2010. Hydroxyl airglow on Venus in comparison with Earth. Planet. Space Sci., doi:10.1016/j.pss.2010.05.004.

Montmessin, F. et al., 2006. Stellar occultations at UV wavelengths by the SPICAM instrument: Retrieval and analysis of martian haze profiles. J. Geophys. Res. 111. doi:10.1029/2005JE002662.

Perrier, S. et al., 2006. Global distribution of total ozone on Mars from SPICAM/MEX UV measurements. J. Geophys. Res. 111, doi:10.129/2006JE002861.

Piccioni, G. et al., 2008. First detection of hydroxyl in the atmosphere of Venus. Astron. Astrophys. 483, 29-33.

Piccioni, G. et al., 2009. Near-IR oxygen nightglow observed by VIRTIS in the Venus upper atmosphere. J. Geophys. Res. 114. doi:10.1029/2008JE003133.

Segura, A. et al., 2007. Abiotic formation of $\mathrm{O}_{2}$ and $\mathrm{O}_{3}$ in high- $\mathrm{CO}_{2}$ terrestrial atmospheres. Astron. Astrophys. 472, 665-679.

Selsis, F., Depois, D., Parisot, J.-P., 2002. Signature of life on exoplanets: Can Darwin produce false positive detections? Astron. Astrophys. 388, 985-1003.

Soret, L. et al., 2010. Venus OH nightglow distribution based on VIRTIS limb observations from Venus Express. Geophys. Res. Lett. 37. doi:10.1029/ 2010 GL042377.

Svedhem, H. et al., 2007. Venus as a more Earth-like planet. Nature 450, 629-632.

Yung, Y., DeMore, W., 1982. Photochemistry of the stratosphere of Venus: Implications for atmospheric evolution. Icarus 51, 199-247.

Yung, Y., DeMore, W., 1999. Photochemistry of Planetary Atmospheres. Oxford University Press, p. 306. 